Tohoku J. Exper. Med., 1961, 73, 215-229

\title{
A Particular Binding of L Cell-Grown Sendai Virus by Host L Cells
}

\author{
(Growth Characteristics of Myxoviruses in \\ Tissue Gulture, 5th Report) \\ By \\ Morio Homma \\ Department of Bacteriology, School of Medicine, Tohoku \\ University, Sendai; Director : Prof. N. Ishida \\ (Received for publication : September 8, 1960)
}

In a previous publication ${ }^{11}$, the growth characteristics of Sendai virus (Myxovirus para-influenzae 1, HVJ) in Earle's L cell cultures have been fully described. Morphological changes followed to the infection were also characterized $^{12)}$. Different from related host-virus systems already described ${ }^{3)}$, these infected cells reproduced egg infectious particles. These L cell-grown particles, however, were different from allantoic membrane-grown virus because they lost infectiousness to the $L$ cell and also hemolytic activity. The former proof was established in examining $L$ cells reinfected with these particles, where any viral antigens i.e. soluble antigen, hemagglutinin and egg infectious particle were not detectable inside the cell. Cyto-hemadsorption was also negative in this reinfection system. Further study conducted by means of fluorescent antibody technique ${ }^{2}$, gave a concordant answer. However, it is also true that when $\mathrm{L}$ cell-grown virus was once passed into the allantoic cavity of fertile egg, lost two activities mentioned above were immediately restored. These series of observation may indicate that the virus produced in $\mathrm{L}$ cell is a kind of host controlled variant.

In order to explain the non-infectiousness of this variant to the $\mathrm{L}$ cell, the experiment to be reported here was conducted. As a result, this variant was shown to be able to adsorb to $\mathrm{L}$ cell again. However, the adsorption feature was rather peculiar. They were adsorbable to the $\mathrm{L}$ cell in the cold, but elutable at warm temperature. Thus the interaction here observed was rather related to that known between a myxovirus and chicken red blood cells. Furthermore, this kind of binding was found to be eliminated at $36^{\circ} \mathrm{C}$ by the action of antibody prepared against Sendai virus. Thus the inhibitoin of the so-called firm binding between this variant and $L$ cell was anticipated to be the case, pro-

本間 守男

This paper is a part of the work presented at the 7 th annual meeting of the Society of Japanese Virologists held in Tokyo, October 1959. 
bably owing to the altered surface structure of this variant. In spite of such a difference, $a$-enzyme activity of the $\mathrm{L}$ cell-grown virus was well preserved when compared to the original egg adapted virus.

\section{MATERIALS AND METHODS}

\section{Virus stocks}

Egg-grown virus (E-Orig.): Fushimi strain of Sendai virus $\left(\mathrm{M}_{12} \mathrm{R}_{1} \mathrm{M}_{3} \mathrm{E}_{20}-\mathrm{E}_{35}\right)$ grown in the allantoic cavity of 10-day-old embryonated eggs was used throughout this study. For the preparation of stock virus, $0.2 \mathrm{ml}$ of an allantoic fluid virus diluted up to $10^{-6}$ was inoculated and incubated for 48 hours at $36^{\circ} \mathrm{C}$. Each stock was assayed both for 50\% egg infectivity dose (EID ${ }_{\text {50 }}$ ) and hemagglutinin (HA) titer. Used harvest usually contained $10^{9.8} \mathrm{EID}_{50}$ and $10^{3.6}$ $\mathrm{HA}$ per $\mathrm{ml}$. Thus the $\mathrm{EID}_{50}: \mathrm{HA}$ ratio (I/A ratio) of the egg-grown virus was $10^{62}$.

$\mathrm{L}$ cell-grown virus (L-Var.): Mature bottle cultures $(200 \mathrm{ml}$ flask) of $\mathrm{L}$ cells were once washed with Hanks' solution and infected with $10 \mathrm{ml}$ of maintenance solution containing one $\mathrm{ml}$ of allantoic fluid virus. After 1 hour period of adsorption at $36^{\circ} \mathrm{C}$, the inoculum was removed as completely as possible, washed 3 times with Hanks' solution, refed with maintenance solution followed by incubation at $36^{\circ} \mathrm{C}$ for 48 hours. At the end of this incubation period, the culture fluids were separated and served as the L cell-grown virus (L-Var.). Different from E-Orig., the harvest of $\mathrm{L}$ cell culture showed some deviation in both $\mathrm{EID}_{\overline{5} 0}$ and HA. However, EID $_{50}$ ranged from $10^{6.5}$ to $10^{7.5}$ and HA ranged from $10^{2.1}$ to $10^{2.7}$. Thus $\mathrm{I} / \mathrm{A}$ ratio calculated with each harvest ranged from 4.5 to 5.2 .

\section{Purification of Egg-and $L$ cell-grown viruses}

The virus used in this experiment was purified by means of ultracentrifugation, unless otherwise stated. Allantoic fluid harvests obtained at 48 hours were centrifuged first at $3,000 \mathrm{rpm}$ for 15 minutes in order to remove the contaminated. debris, and after a span at $40,000 \mathrm{~g}$ for 30 minutes, the virus was precipitated. Obtained pellets were resuspended with $0.01 \mathrm{M}$. phosphate buffered saline of $\mathrm{pH}$ 7.1 (PBS) and clear supernate was used for the study. With L cell-grown harvests, almost the same purification procedure as $\mathrm{E}$-Orig. was followed, except for the final ultracentrifugation procedure made at $100,000 \mathrm{~g}$ for 30 minutes.

\section{Egg infectivity titrations}

The egg infectivity was determined by inoculating 5 groups of 4 eggs $0.2 \mathrm{ml}$ of each with a serial tenfold dilution. After 72 hours of incubation at $36^{\circ} \mathrm{C}$, allantoic fluid was removed from each egg and tested for hemagglutinin. The EID $_{50}$ was calculated by the method of Reed and Muench.

\section{Hemagglutinin titrations}

Hemagglutinin titrations were carried out by Salk's pattern method. How- 
ever, when more precise examinations were necessary, more critical method proposed by Horsfall and Tamm ${ }^{4}$ was used.

\section{Tissue cultures}

Earle's L cells have been maintained in this laboratory by means of trypsinization. The growing medium was composed of $10 \%$ bovine serum and $90 \%$ YLE solution. For virus growth, 95\% YLE with $5 \%$ inactivated horse serum was used as the maintenance solution. Detailed method has been already described in the preceding report ${ }^{1}$.

\section{Antibody preparations}

Rabbits were inoculated intravenously with $5 \mathrm{ml}$ of allantoic fluid harvest titered $2048 \mathrm{HA}$ units per $\mathrm{ml}$, three times at four day intervals. The serum was drawn by cardiac puncture one week after the last immunization. The hemagglutination inhibition titer of the obtained sera was around 5,000 units per ml against 4 hemagglutinin unit of egg adapted virus. This preparation was shown to be inert against normal $\mathrm{L}$ cell cultures.

\section{Density gradient centrifugation}

Density gradient columns were made by layering five sucrose solutions at the concentrations of $60,50,40,30$ and $20 \%$ in the PBS. Each solution was added to the $\mathrm{SW}$ centrifugal tubes in order of sucrose concentrations, and occupied from bottom to upwards $0.5,1,1,1$ and $0.5 \mathrm{~cm}$ of depth, respectively. After the solutions were layered, the tubes were allowed to stand overnight at $4^{\circ} \mathrm{C}$ in order to obtain the gradual gradient. On the next day, a layer of virus material purified as described above was floated on the top of the column in 0.5 $\mathrm{cm}$ of depth. After centrifugation at $100,000 \mathrm{~g}$ for 1 hour in a cold condition, the samples were removed by puncture through the wall of the plastic tube with an appropriate width and each fraction was tested for hemagglutinin and egg infectivity.

\section{EXPERIMENTAL}

\section{Possible adsorption of the $L$ cell-grown virus onto $L$ cells}

In the preceding paper, the fact that $\mathrm{L}$ cell-grown virus is not able to infect $\mathrm{L}$ cell again has been pointed out. This was thought rather peculiar, because these particles still hold the activity to infect egg embryos again, when inoculated into the allantoic cavity. Further analysis of this fact has been attempted here in an effort whether this variant virus can adsorb to the $\mathrm{L}$ cell again.

For this purpose, both E-Orig. and L-Var. were examined in the same manner. 
TABLE I. Adsorption Rate of Both Egg Adapted and L Cell-grown Sendai Virus to the L Cell Suspension with Various Multiplicity

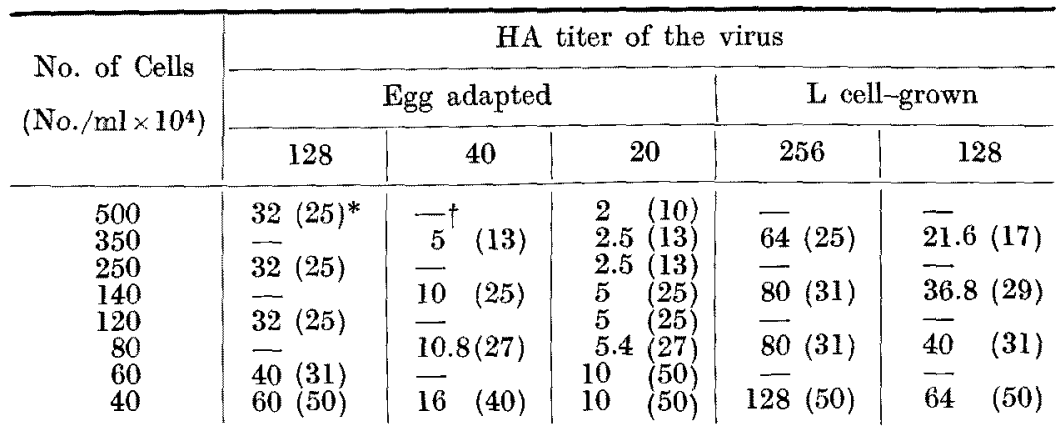

* Cells in one $\mathrm{ml}$ of PBS mixed with $1 \mathrm{ml}$ of virus in vitro, held one hour $4^{\circ} \mathrm{C}$, then the $\mathrm{HA}$ titer of the supernate was measured. Figures in parentheses indicate the unadsorbed amount of $\mathrm{HA}$ in percentage. Horsfall and Tamm's procedure was employed for HA titration.

$\dagger$ Not done.

One $\mathrm{ml}$ aliquots of various concentration of both viruses were added to $1 \mathrm{ml}$ of $\mathrm{L}$ cell suspensions made in PBS. Concentration of $\mathrm{L}$ cell was also changed. After one hour period of adsorption at $4^{\circ} \mathrm{C}$, with gentle agitation at every 15 minutes, the mixtures were centrifuged at $3,000 \mathrm{rpm}$ for 2 minutes in a cold and the supernates were tested for hemagglutinins. Here Horsfall and Tamm's procedure $^{4)}$ was employed for hemagglutinin titration to assure the exactness. Table I shows this result. As it is evident from the Table, the adsorption rates of both viruses onto $\mathrm{L}$ cell suspensions were rather related and corresponded well with the amount of adsorbent.

Thus the result indicates a possible adsorption of $\mathrm{L}$ cell-grown virus onto $\mathrm{L}$ cell when the cell and virus, both in suspension state, are left in the cold.

The effect of the relative amount of $L$-Var. to E-Orig. in inducing the interference state

The former experiment revealed the fact that $L$ cell-grown virus was able to adsorb to the $\mathrm{L}$ cell, at least in the cold. However, it is also known that the production of new virus is not provable in this system. Then the next analysis should be undertaken whether this kind of adsorption equilibrium can establish an interference state against egg-grown virus. For this purpose, some preliminary studies were conducted to test the interfering activity of $\mathrm{L}$ cell-grown virus.

Firstly the fact has been revealed that the $\mathrm{L}$ cell which was infected with L-Var. reduced the virus yield when challenged with E-Orig.. Namely, L cellgrown harvests of Sendai virus were known to interfere the HA production of 
egg-grown virus. Secondly the interfering activity was shown to be accompanied with virus particle itself but not with the supernatant when the $\mathrm{L}$ cell harvest was centrifuged at $100,000 \mathrm{~g}$ for 60 minutes. Thus the participation of interferon $^{5 / 6)}$ ) was excluded. On the basis of such observations, the final run to know the quantitative relationship between $\mathrm{L}-\mathrm{Var}$. and $\mathrm{E}-\mathrm{Orig}$. to give rise to interference was examined. To this end, the purified harvest of the infected $\mathrm{L}$ cell culture was inoculated into fresh $\mathrm{L}$ cell culture tubes at various concentration. After 1 hour period of incubation at $36^{\circ} \mathrm{C}$, each tube was washed three times with $2 \mathrm{ml}$ of Hanks' solution, and challenged with E-Orig.. After additional 1 hour of incubation, tubes were washed again as described above in order to eliminate the residual portion of the second inoculum. Then they were refed with fresh maintenance solution. After further 96 hours of incubation, fluids were removed and tested for hemagglutinins in contrast with the one from which the first virus was omitted. The virus yield of the control culture was taken as $100 \%$ and the growth percentage of the each tested tube was calculated. The results of all such experiments were summarized in Fig. 1. From these results, it was

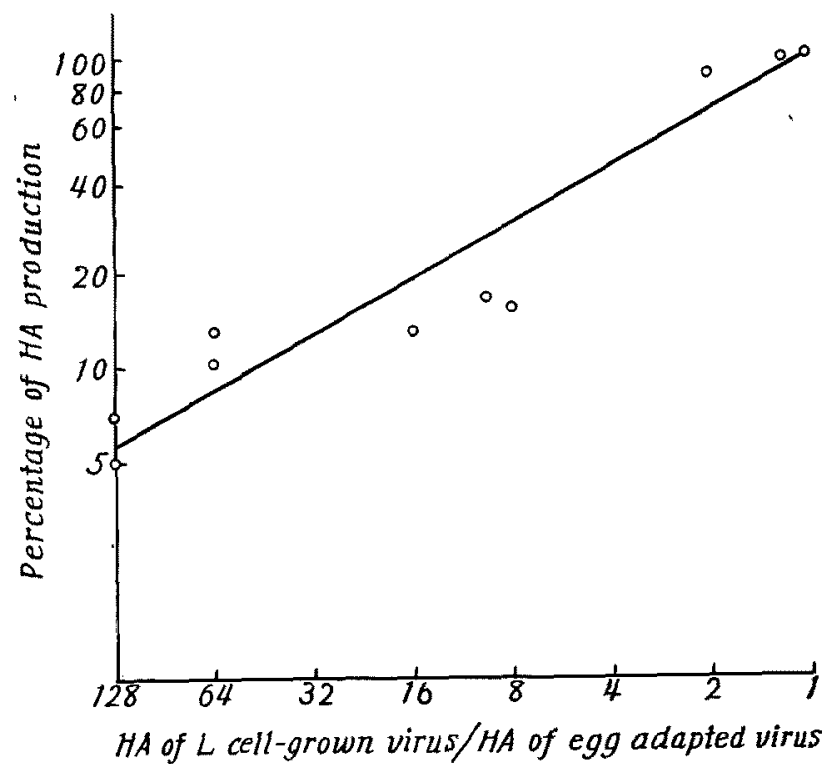

Fig. 1. Interfering activity of the $\mathrm{L}$ cell-grown virus against the HA production of the egg-adapted virus given one hour later.

concluded that an interference state could be induced to $\mathrm{L}$ cells with L-Var. when incubated at $36^{\circ} \mathrm{C}$ for one hour even after thorough washings. Also the fact that larger amount of L-Var. in a sense of HA was required to induce a complete interference against E-Orig. was noticed. The degree of interference was 
also known to be in proportion to the ratio of the first virus to the second virus.

Effect of the time intervals between the first and the second infection upon the interference

In an effort to know the mechanism of this interference, the effect of the time intervals between inoculation of the first and the second virus upon virus yield was examined. To do this, a lot of culture tube were infected with $\mathrm{L}$ cell-grown virus (finally $512 \mathrm{HA}$ units $/ 10^{\circ}$ cells) and were incubated at $36^{\circ} \mathrm{C}$. At various hours thereafter, they were taken ont, washed and then challenged with $4 \mathrm{HA}$ units of $\mathrm{E}$ Orig. Virus amount given in the first inoculum was enough to induce interference against the second inoculum. On the basis of a preliminary observation, the interfering activity when the challenge was made 1 hour after the first virus inoculation was taken as $100 \%$. Thus the degree of growth inhibition of the second virus was calculated and plotted in Fig. 2. As a result, the degree of in-

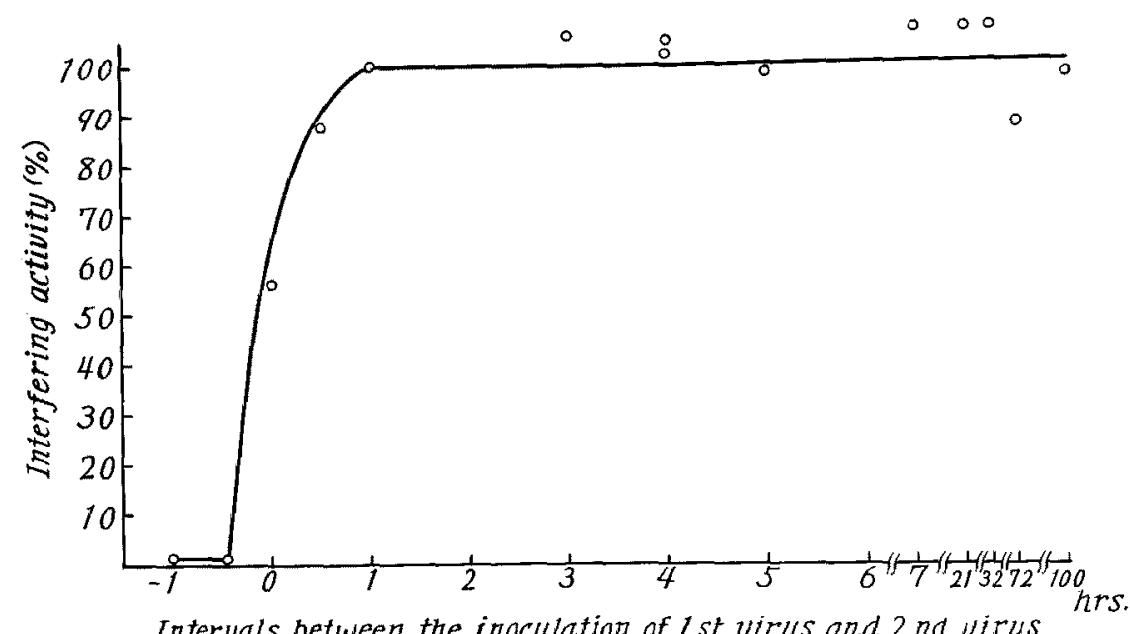

Fig. 2. Adsorption rate of interfering virus.

terference when the first and the second virus were inoculated simultaneously was calculated as more than $50 \%$. When the challenge virus was inoculated 30 minutes ahead of the inoculation of $\mathrm{L}$ cell-grown virus, the interference did not occur. As it is evident in the Fig. 2, the interfering activity reached to the maximum by 1 hour and this situation was continued at least up to 100 hours.

The curve here illustrated should be also understood as the adsorption curve of $\mathrm{L}$ cell-grown virus. In the preceding report ${ }^{11}$, the time required for full adsorption of egg adapted virus to the same cell was determined as 60 minutes. At 30 minutes the adsorption rate was around 80 to $90 \%$. Taken together, adsorption sequence of both egg- and $\mathrm{L}$ cell-grown virus will be said to Le quite related.

Failed attempt to produce interferon in $L$ cell infected with $L$ cell-grown virus 
To determine the nature of interference described above, it was thought to be necessary to examine the participation of interferon, noticed by Isaacs' school(5)7). Thus the possible liberation of interferon when normal $\mathrm{L}$ cell was infected with L-Var. was tested in detail.

Ten $\mathrm{ml}$ of $\mathrm{L}$ cell-grown virus purified by means of ultracentrifugation containing $10^{8.7} \mathrm{EID}_{50}$ per ml was inoculated into $\mathrm{L}$ cell culture bottles $(200 \mathrm{ml}$ ) and 1 hour after adsorption, the inoculum was removed. These cells were washed thoroughly by Hanks' solution and then refed with fresh maintenance solution. Harvests from 12, 24 and 72 hours of incubation were served as test materials for interferon which might be liberated into the fluid. On the other hand, at the end of each indicated period, the cell layers were washed by Hanks' solution, homogenized by means of glass homogenizer and resuspended at original volume by maintenance solution. After low centrifugation, the supernates were obtained and tested to see whether interferon was produced inside the cell. To carry out the test, both culture fluid and cell extract were first inoculated into the fresh $\mathrm{L}$ cell culture tubes without any dilution. After 24 hours of incubation at $36^{\circ} \mathrm{C}$, egg adapted virus containing $2 \mathrm{HA}$ units per $\mathrm{ml}$ was challenged. Virus yield of each tube at 96 hours was compared with that of control which was not pretreated. As a result, no significant differences were observed between each experimental group and the control one. Thus it was concluded that the production of interferon was not provable to an appreciable amount, at least in the system employed here.

Difference found between E-Orig. and $L$-Var. at the time of elution from suspended $L$ cell

L-Var. is now known to be able to adsorb to $\mathrm{L}$ cells both in the cold and warm. At the latter state of adsorption, interference against E-Orig. was established, without production of interferon. However, large amount of HA was required to induce the interference state.

In order to reveal the character of this adsorption feature, L-Var. was once adsorbed to the suspended $L$ cells in the cold and elutability at warm condition was examined with the control of E-Orig.

One $\mathrm{ml}$ aliquots of both L-Var. and E-Orig. in PBS solution, each titrated $1024 \mathrm{HA}$ units $/ \mathrm{ml}$, were added to the equal amount of $\mathrm{L}$ cell suspensions in a concentration of $6 \times 10^{6} / \mathrm{ml}$ and left for 1 hour at $4^{\circ} \mathrm{C}$ under gentle shaking at every 15 minutes. At the end of this period, the mixtures were centrifuged in the cold, and the supernatant fluids were separated for the titration of unadsorbed hemagglutinins. Then, two $\mathrm{ml}$ of prewarmed PBS was added to the sediment and elution of the virus from the cell was attempted at $36^{\circ} \mathrm{C}$. At every 20 minutes intervals, incubated virus cell mixtures were centrifuged and the supernates were tested for elutable hemagglutinins. The sediments were refed 
with fresh prewarmed PBS and the same incubation procedure was repeated four times in total. After the completion of these elution trials, the cell suspensions were superinfected with E-Orig. titered $512 \mathrm{HA}$ units $/ \mathrm{ml}$ with the control of normal cell. Allowing adsorption for 1 hour at $4^{\circ} \mathrm{C}$, unadsorbed virus amount was measured. Obtained results were also illustrated in Table II.

TaBLe II. Adsorption and Elution of Both Original and Variant Sendai Virus to and from L Cell Suspension

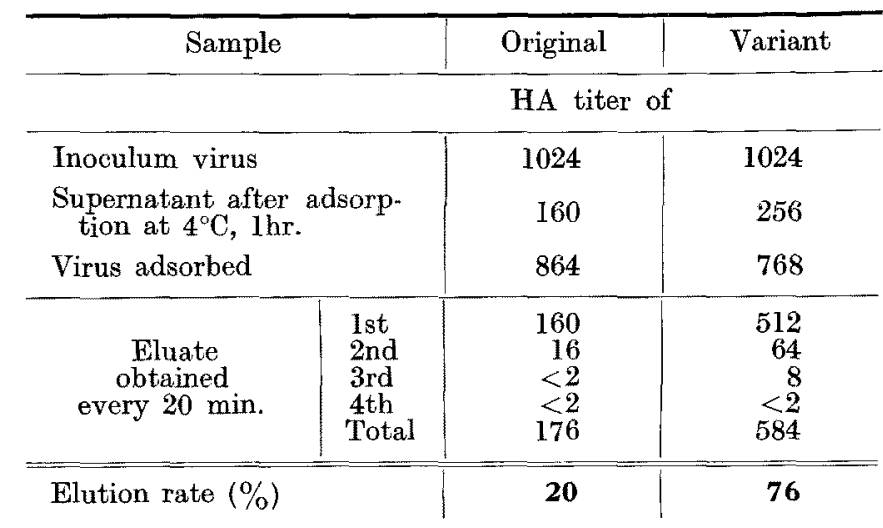

Adsorption Rate of Challenge Virus

\begin{tabular}{l|c|c|c}
\hline Initial cell treatment with & Original & Variant & PBS \\
\hline & HA titer of \\
\hline \begin{tabular}{l|c|c|} 
Inoculum virus \\
Supernatant after adsorp- \\
tion at $4^{\circ} \mathrm{C}$, lhr.
\end{tabular} & 512 & 512 & 512 \\
\hline Adsorption rate $(\%)$ & 256 & 256 & 128 \\
\hline
\end{tabular}

Adsorption rate of both E-Orig. and L-Var. at $4^{\circ} \mathrm{C}$ was not so different each other and $84 \%$ and $75 \%$ was calculated respectively. However, when the amount of eluted virus was taken into account, quite a difference was noticed between these two inocula. More than $76 \%$ of the adsorbed virus was elutable with L-Var. but only 20\% with E-Orig. From this result, it might be possible to conclude that L-Var. could adsorb onto L cell but at least the larger fraction of this inoculum did not proceed further to firm binding or/and penetration. This conception is in good agreement with the observation that $\mathrm{L}$ cell infected with L-Var. could not replicate any viral antigens.

Further, when the capacity of these treated cells to adsorb newly added egg-virus was tested as described above, a concordant result was obtained. These treated cells, one with E-Orig. the other with L-Var., did not adsorb the new inoculum as well, when compared to the control. It was illustrated in the lower section of Table II. Although the data represented here are not fully 
elaborated in a quantitative sense, the difference in adsorbing the new inoculum when compared to the non-treated cell, was secured.

Possible explanation of the interfering mechanism here observed will be the steric hindrance or/and impairment of the receptor site. Added L-Var. will be in the state of equilibrium with the $\mathrm{L}$ cell at $36^{\circ} \mathrm{C}$ and adsorption and elution cycle will be repeated with larger portion of these particles. Eventually, production of interferon in this state was negligible, as pointed out before.

Enzymatic activity of $L$-Var.

In the above experiment, L-Var. was suggested to have a full enzymatic activity allowing the elution from suspended $\mathrm{L}$ cell at warm condition. In the preceding report'1', the same conclusion was drawn when chicken and guinea pig red cell was used as a receptor site, regardless of the disappearance of hemolytic activity. Thus eluting activity both from red blood cell and $\mathrm{L}$ cell was well preserved with L-Var. as same degree as the E-Orig.

In order to assure this finding, enzymatic activity of L-Var. on an $\alpha$-inhibitor in solution was compared with that of E-Orig.. An extract of mouse lung was used as the source of $\alpha$-inhibitor, as this is the only one potent inhibitor against this virus ${ }^{8}$. Lungs were first resected from 15 adult mice and homogenized by means of a mortar and pestle with sea sand as an abrasive. Finally $20 \%$ suspension was made by PBS, followed by centrifugation at 2,000 rpm for 20 minutes. This supernate was used as an inhibitor. The inhibitor titer was 256 units $/ \mathrm{ml}$ when assayed against $4 \mathrm{HA}$ units of E-Orig.. As this inhibitor has been already proved to be stable when heated at the temperature of $56^{\circ} \mathrm{C}$ known to be enough

TABLE III. $\alpha$-Enzyme Activity of Both Egg-adapted and L Cellgrown Virus Assayed with Mouse Lung Extract as the Substrate

\begin{tabular}{l|c}
\hline Treatment* & $\begin{array}{c}\text { HAI-titer against } \\
\text { egg-adapted } \\
\text { Sendai virus }\end{array}$ \\
\hline None & 256 \\
\hline Heating at $56^{\circ} \mathrm{C}$ for $30 \mathrm{~min}$. & 256 \\
\hline E-Orig. \\
L-Var. $\}$ for 30 min. & 4 \\
\hline E-Orig. $\{$ for 60 min. & 4 \\
L-Var.
\end{tabular}


to destroy hemagglutinin activity of Sendai virus, the remaining activity of the inhibitor after the enzymatic action of virus was easily assayed. To do this, half a $\mathrm{ml}$ of each E-Orig. and L-Var. (2560 HA units/ml) was added to an equal amount of the lung extract and the mixtures were incubated in the water bath at $36^{\circ} \mathrm{C}$. At indicated incubation period, i.e. 30,60 and 120 minutes respectively, the mixtures were taken out and heated at $56^{\circ} \mathrm{C}$ for 30 minutes to destroy the remaining hemagghutinins. Then they were tested for remaining inhibitor titer with $4 \mathrm{HA}$ units of E-Orig.. These results were shown in Table III and no difference was found between E-Orig. and L-Var. with regard to the $\alpha$-enzyme activity.

\section{Elimination of the interference state by anti-viral rabbit serum}

Marked difference between E-Orig. and L-Var. so far recognized was only in respect of elutability from the L-cell. L-Var. is known to be adsorbed onto $\mathrm{L}$ cells as E-Orig. but is not able to form the firm binding with $\mathrm{L}$ cell. To confirm the observation and also to know the strength of observed equilibrium state existing at $36^{\circ} \mathrm{C}$, the following experiment was conducted.

Firstly, L cell was infected with L-Var. and after an appropriate incubation period, these cell-virus complexes were treated with antiviral serum. Residual antibody was washed thoroughly and then they were challenged with E-Orig. After 96 hours of incubation, growth of the challenged virus was measured to see the degree of interference. When the degree of interefrence was compared to each control, in which the L-Var.-cell complex was washed with normal rabbit serum instead of immune rabbit serum, the effect of specific antibody was estimated.

To do this, the cell layers infected with L-Var. were prepared in a large amount. At 5, 10, 20, 30,60 minutes and 16 hours after the infection, they were washed thoroughly 2 times with Hanks' solution and immediately received anti-viral rabbit serum diluted 1:10 in maintenance solution. The control tubes were treated with the same procedure but substituted with normal rabbit serum. After thirty minutes of incubation at $36^{\circ} \mathrm{C}$, sera were removed, and the tubes were washed 2 times with Hanks' solution and challenged with $4 \mathrm{HA}$ units of E-Orig.. Allowing to expose for 60 minutes with E-Orig., the cells were refed with fresh maintenance solution and were incubated up to 96 hours in each. At the end of this period, harvests from each tube were tested for hemagglutinin. Obtained results were shown in Fig. 3. Each circle represented the percentage of virus yield against that of control culture which received only E-Orig.. The curve written as "control" represents the velocity in establishing the interference state against E-Orig. with L-Var.. When compared to the experiment shown in Fig. 2, only one difference in carrying out this control experiment was the treatment with normal rabbit sera for a period of 30 minutes. In spite of this 


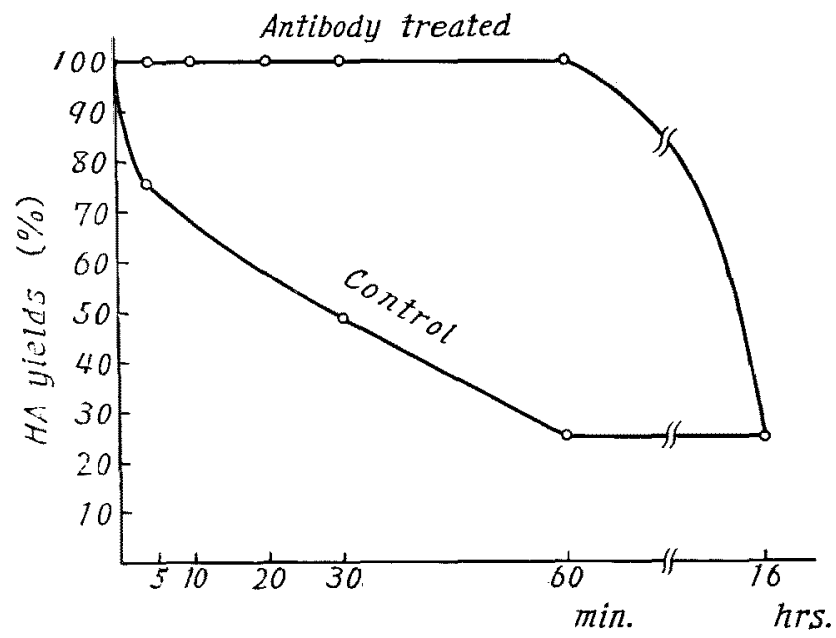

Fig. 3. Effect of viral antibody prepared in rabbit upon interference phenomenon.

treatment, the curve was quite similar to that shown in Fig. 2, though the curve was illustrated upside down. Contrary to this, one can notice the fact that the interfering activity of L-Var. is easily eliminated by antiviral serum. The cultures received immune sera reduced their interfering activity markedly at least for a period of 60 minutes. Unfortunately, the time at which the antibody becomes ineffective upon the interference was undetermined. At 16 hours, however, viral antibody could no longer inhibit interference. Possible explanation for this result is that antibody may be effective upon free virus around the surface of the $L$ cell and as they are in such a state, further development of the infectious process was inhibited. However, at 16 hours antibody treatment is no more effective against interference when receptors have been possibly destructed by surface bound L-Var..

Density distribution of $L$-Var.

It has been already noticed that the particles of L-Var. were lighter than that of E-Orig. in the field of ultracentrifugation ${ }^{1)}$. In this connection, when L-Var. was centrifuged at $20,000 \mathrm{~g}$ for 30 minutes, $49 \%$ of total hemagglutinin was left in the supernatant where under the same condition, more than $99 \%$ of E-Orig. was sedimentable. Secondly, the I/A ratio of the lighter fraction has been also known to be low with any harvest of Sendai virus. On the basis of these observations, the centrifugation at $100,000 \mathrm{~g}$ for 30 minutes was customly employed in order to recover about $99 \%$ of hemagglutinin of $\mathrm{L}$ cell harvest and this kind of precipitate was used throughout the experiment. However, the fact noticed in pursuing the growth of E-Orig. in L cells ${ }^{1}$, that the hemagglutinin which was characterized by non-infectiousness to eggs and detectable 

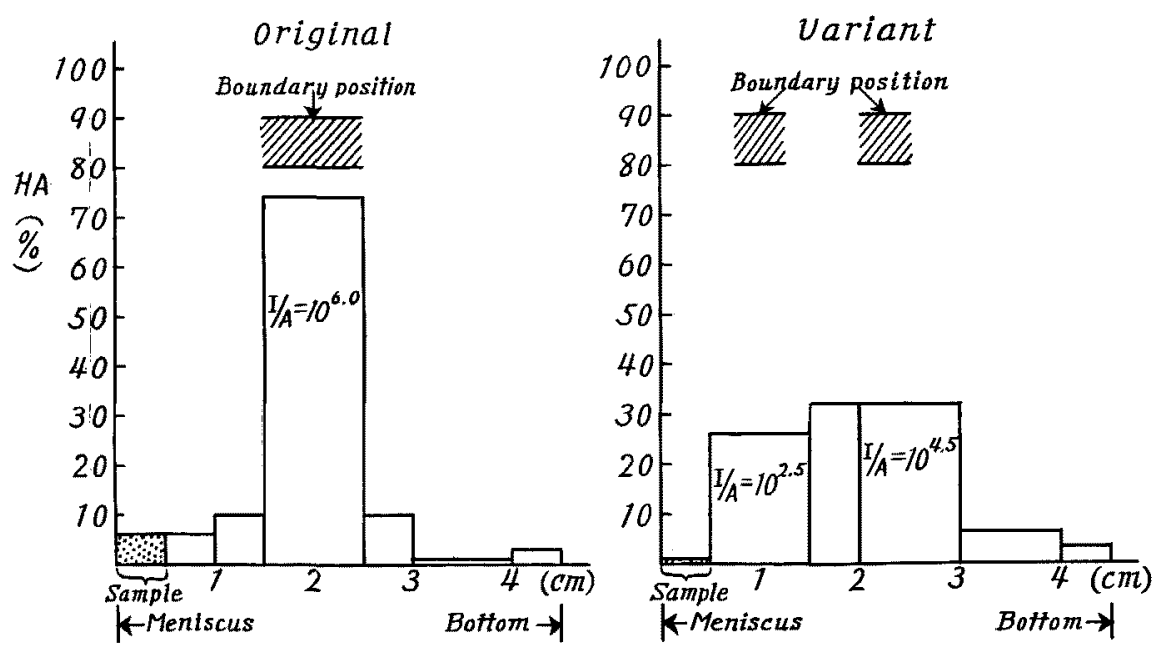

Fig. 4. Difference in density distribution between the original and variant.

Density gradient columns were made by layering five sucrose solutions at the concentrations of $60,50,40,30$ and $20 \%$ in the PBS and occupied from bottom to upwards $0.5,1,1,1$ and $0.5 \mathrm{~cm}$ of depth, respectively. One half $\mathrm{ml}$ of virus was floated and centrifuged for 1 hour at $100,000 \mathrm{~g}$. In the figure, I/A stands for $\mathrm{EID}_{50} / \mathrm{HA}$.

in culture fluid at an early period of infection is at least a part of L cell harvest, should be taken into account. The liberation of such hemagglutinins was observed at 8 to 9 hours of infection and was three hours ahead of the appearnace of egg infectious particles ${ }^{1}$. Thus the $\mathrm{L}$ cell harvests obtained at 48 hours and used in this experiment should be contaminated with these non-infectious particles. For the purpose of separating these non-infectious hemagglutinins from the $L$ cell harvest, sucrose density gradient centrifugation was repeated as described in the section of materials and methods. One of the typical results obtained so far was illustrated in Fig. 4. In the Fig. 4, the shaded portion showed the visible zones. As a result, quite different feature was found as for the density distribution of hemagglutinin, between E-Orig. and L-Var.. With E-Orig. the hemagglutinin was found in relatively narrow width in accordance with the visible zones. Infectivity was also recoverable in this fraction and the I/A ratio was calculated as $10^{6.0}$. On the contrary, two visible zones were obtained with LVar. and wide distribution of hemagglutinin was characteristic. The I/A ratio of the low density fraction was lower than that of the main fraction. In repeating the similar experiments, various hemagglutinin distributions were obtainable with $\mathrm{L}$ cell harvests due to the different steepness of the gradient. However, the above conclusion was consistently obtained.

Then the most dense fraction was isolated from $\mathrm{L}$ cell harvests through this kind of procedure and was tested for the infectivity to the $\mathrm{L}$ cell. As a result, 
this kind of fraction also failed to infect $\mathrm{L}$ cell again. The related conclusion was once pointed out in a previous publication ${ }^{1)}$, where the heaviest fraction of $\mathrm{L}$ cell harvest was used to reinfect $\mathrm{L}$ cell.

\section{DISCUSSIONS}

First proposal of this experiment was to explain the non-infectiousness of $\mathrm{L}$ cell-grown virus to the $\mathrm{L}$ cell, in spite of well-preserved infectiousness to allantoic membrane. Direct answer will be the impaired activity of this virus to induce firm binding with $\mathrm{L}$ cells. Thus the discussions should be first confined to this kind of particular adsorption state.

Although striking similarities between certain bacterial viruses and influenza virus in the condition of adsorption onto the host cells have been pointed out by various authors ${ }^{810}$, critical description of the adsorption state of inAluenza virus was firstly made by Ishida and Ackermann11/21). They claimed two phases of cell entry with influenza $A$ virus. When virus becomes attached to chorioallantoic pieces in the cold, it soon ceases to be detachable by RDE but remains susceptible to inactivation by immune serum. If the temperature is raised to $37^{\circ} \mathrm{C}$ the virus soon becomes inaccessible to the antibody. Just the same situation as their first phase has been found here between $\mathrm{L}$ cell-grown virus and $\mathrm{L}$ cell, even at $36^{\circ} \mathrm{C}$. The $\mathrm{L}$ cell used in this experiment, has been maintained for these 4 years under the same condition and has been shown to be susceptible to the egg adapted parent virus in the same degree. Thus the peculiar adsorption here recognized should be understood as the defective change of $L$ cell-grown virus.

However, this kind of adsorption equilibrium produced at $36^{\circ} \mathrm{C}$ was also shown to make the cells insusceptible to superinfection of allantoic fluid virus when challenged 1 hour later. In the recent review made by Isaacs, at least three distinct mechanisms of interference have been characterized ${ }^{13}$. In his definition, the first type was the one just competing the receptor site. For example, as described by Baluda1415), u.v. irradiated Newcastle disease virus in such a way that it remains its enzymatic activity, is able to remove virus receptors from susceptible cells such as chick embryo fibroblast, by its enzymatic action. Interference therefore results from the fact that the challenge virus can not be adsorbed onto the cells. This kind of explanation will be most plausible for this experimental result because of the following facts. The interfering activity of the $L$ cell harvest was not found in the supernatant fluid after ultracentrifugation at $100,000 \mathrm{~g}$ for 30 minutes and the degree of interference was in proportion to the number of virus particles. The time interval between the first and the second virus required for the induction of maximal interference was 60 minutes. When the second virus was inoculated 30 minutes ahead of the first virus inoculation, the interference was no more induced. Further, addition of 
anti-viral serum resulted in an inhibition of interference. From these results, the explanation described above was adopted. Elutability of these variant particles not only from red cell but from $\mathrm{L}$ cell was proved. Thus the enzymatic activity should be well preserved with these particles, and the fact was again assured when mouse lung homogenate was used as a substrate in examining its enzymatic activity.

The fact that a variant virus produced in mouse fibroblast $\mathrm{L}$ cell cultures is defective not only in hemolytic activity but also in establishing firm binding with uninfected $\mathrm{L}$ cell is the matter to be considered for the generalization. Recent studies performed in this laboratory on the character of hemadsorption type 2 virus reproduced in persistent infection in HeLa cell cultures revealed the same fact. When HeLa cells were first infected with HA 2 virus propagated in monkey kidney cell cultures, HeLa cells were soon made to liberate hemagglutinins, for a large number of duplications. These hemagglutinins were infectious to monkey kidney cells but hardly infections to normal HeLa cells. Although this kind of defective variation resulted in inducing non-infectious state to the mother cell was secured in the field of bacteriophage ${ }^{16}$, the fact has never been described in the field of animal virology.

Well-preserved enzymatic activity here proved with the variant had nothing to do to get into the firm binding by the host cell. Then the question arises whether the loss of hemolytic activity found with L-Var. should be correlated to the defective change in firm binding or not.

From several observations made on the hemolytic activity of egg-born Sendai virus, this activity was believed to be located rather as an extrinsic entity to be removable by an alcohol treatment. In a serological sense, the hemolytic entity of the virus particle has been shown to have the shared antigenicity with allantoic membrane. The hemolytic activity has been detectable only with virus born in cells of allantoic membrane and liberated into the allantoic cavity. Sendai virus produced in the cells such as L, FL, Hela, human embryonic lung, chicken fibroblast and monkey kidney, were all void of hemolytic activity. In spite of this fact, virus produced in human embryonic lung and monkey kidney cells has been shown to be infectious to $\mathrm{L}$ cells.

These considerations may indicate the possible dissociation of these 2 activities, one hemolytic activity, the other infectivity to the $\mathrm{L}$ cell.

\section{SUMMARY}

Egg adapted Sendai virus is fully infectious to both chick embryos and Earle's L cell. In the latter system, reproduction of egg infectious particles has been already proved. However, the $\mathrm{L}$ cell-grown virus differs from parent virus in its non-infectiousness, when $\mathrm{L}$ cell was used again for its reproduction. Thus the study was conducted to reveal the characters of this L cell-grown virus. 
First of all, it was shown that adsorption of this particular virus to the $\mathrm{L}$ cell did occur in the same efficiency as that of egg adapted virus when tested in the cold. Possible adsorption to the $\mathrm{L}$ cell was again confirmed by testing the interfering activity of the $\mathrm{L}$ cell infected with $\mathrm{L}$ cell-grown virus at $36^{\circ} \mathrm{C}$, where HA production of challenged egg virus was used as an indicator. However, adsorption feature of the $\mathrm{L}$ cell-grown virus to the $\mathrm{L}$ cells was also shown to be quite characteristic. Adsorbed virus once proved in the cold was found to be elutable at $36^{\circ} \mathrm{C}$, as was the case between a myxovirus and chicken red blood cells. Furthermore, this kind of adsorption was found to be eliminated by treatment with immune serum prepared against Sendai virus.

Thus the $\mathrm{L}$ cell-grown virus was anticipated to be not equipped enough as egg adapted virus to invade the $L$ cell again. Even when large amount of $L$ cell grown harvest was purified by density gradient centrifugation, most dense particles highly infectious to chick embryos failed to do so.

Receptor destroying activity of this variant, so far examined by biological procedure, was not different from that of parent virus.

\section{ACKNOWLEDGEMENT}

The author is indebted to Prof. N. Ishida for his guidance throughout the course of this work.

\section{References}

1) Ishida, N. \& Homma, M., Tohoku J. Exp. Med., 1961, 73, 56.

2) Ōsato, T. \& Ishida, N., Tohoku J. Exp. Med, in press.

3) Henle, G., Girardi, A. \& Henle, W., J. Exp. Med., 1955, 101, 25.

4) Horsfall, F.L. \& Tamm, I., J. Imm., 1953, 70, 253.

5) Isaacs, A. \& Lindenmann, J., Proc. Royal Soc., B, 1957, 147, 258.

6) Isaacs, A., Lindenmann, J. \& Valentine, R.C., Proc. Royal Soc., B, 1957, 147, 268.

7) Burke, D.C. \& Isaacs, A., Brit. J. Exp. Path., 1958, 39, 78.

8) Satō, S., Virus, $1958,8,48$.

9) Puck, T. \& Sagik, B., J. Exp. Med., 1953, 97, 807.

10) Luria, S.E. \& Delbrïck, M., Arch. Biochem., 1942, 1, 207.

11) Ishida, N. \& Ackermann, W.W., J. Exp. Med., 1956, 104, 501.

12) Ackermann, W.W., Bact. Rev., 1958, 22, 223.

13) Isaacs, A., Virus Growth and Variation, Cambridge University Press, London, $1959,102$.

14) Baluda, M.A., Virology, 1957, 4, 72.

15) Baluda, M.A., Virology, 1959, 7, 315.

16) Luria, S.E. \& Human, M.L., J. Bact., 1952, 64, 557. 